\title{
Autonomous Institutions? Local Ownership in Higher Education in Eastern Indonesia
}

\author{
Juliette Koning \\ Oxford Brookes University \\ Egide Maassen \\ VU University Amsterdam
}

In 2003 the Indonesian Directorate General of Higher Education launched a new strategy with the aim of improving quality, access, and equity in higher education. It was anticipated that providing higher education institutions with an autonomous status would enable them to manage their own organization and sources of income leading to more efficient and effective implementation of academic activities. This article discusses how staff members of eight public universities and polytechnics in Eastern Indonesia make sense of developments towards greater autonomy. The research investigated the perceived rationale for the move towards greater autonomy, and the main challenges and obstacles expected at an institutional and personal level. Positioned within an organizational embeddedness framework, the research identifies three impediments for a readily acceptance of the change: a history of centralized control, a specific institutional "culture", and questions of local ownership. Consequently the article argues that autonomy in this case is met with ambiguity; it is simultaneously perceived as threatening (job loss, new job requirements, leadership) and as empowering (finally being able to set own institutional objectives).

\section{INTRODUCTION}

During the New Order regime (1968-1998) in Indonesia, developments in higher education were directed by long-term strategies designed by the Directorate General of Higher Education (DGHE). The first long-term plan (1975-1985) was associated with the New Order development policy and focused on the role of higher education in national development. The second strategy (1986-1995) intended to improve the quality of tertiary education, while the third strategy (19962005) became known for launching a new paradigm. This new paradigm consists of five pillars of reform: autonomy, accountability, accreditation, quality and evaluation (Beerkens, 2002, p. 24). Before the end of this third term however and related to the reform era (reformasi) that set in after the demise of the New Order regime in 1998, a basic framework for higher education development (2003-2010) was drawn up. This strategy presented an extensive package of 
reforms in management, financial affairs and the quality of higher education in Indonesia. A core issue was the decentralization of public higher education institutions with the aspiration of transforming them into autonomous institutions. This basic framework reflects Indonesia's transition towards a democratic society while at the same time it echoes new public management discourse by stressing the need to become competitive through knowledge creation, a focus on management processes that encourage innovation, efficiency and excellence, and with the role of the central government shifting from regulating towards enabling and facilitating.

The aim of this article is to explore how these developments towards greater autonomy in higher education are perceived within the designated institutions, in this case several higher education institutions in Eastern Indonesia. We know hardly anything about how those working within higher education institutions make sense of the changes that they are asked to implement and how this relates to historical, political, social and economic developments in Indonesia and changes in Higher Education globally. This is also where this article contributes empirically to broader debates on autonomy in higher education and the impact of new public management thinking on this sector. Whereas the managerial perspective dominates these debates, this study provides a bottom-up approach and gives voice to those involved.

The Indonesian case, and in particular the study among Eastern Indonesian institutions, is relevant first of all, because Indonesia is in a transition phase after 30 years of centralized political control under the New Order regime. This raises questions on the impact of that legacy on programs directed towards greater autonomy such as recently developed for higher education. Secondly, Indonesia offers an interesting example in the discussion about the "applicability" of new public management in non-Western contexts. And finally, the Eastern Indonesian setting is relevant because it brings in regional diversity for a country that covers a region as encompassing as Europe which raises serious questions on "national" policy making. What is more, knowledge on Indonesia's higher education sectors is predominantly based on studies among the more advanced and more elitist institutions on the island of Java.

With a history of half a century of authoritarian and centralist governments under former Presidents Sukarno (1945-1967) and Suharto (1968-1998), dependencies, practices and routines (nepotism, institutional inertia, fear, upwards delegation) developed in Indonesia, which might diverge with moves towards greater autonomy. Since greater autonomy often means the "replacement of central authority with local power" (Welch, 2007, p. 667) the broader question is how this local power will be distributed and who, after decades of centralized governance, feels responsible to take the lead? This turns our attention to issues of "local ownership", or in other words issues of responsibility, commitment, participation, and locally owned priorities. Local ownership as a concept circulates in particular in development aid discussions where it refers to "acceptance of responsibility through the process of stakeholder participation, empowerment and consensus" (Singh, 2002, p.48). Keywords are commitment, participation, locally owned priorities, leadership and capacity building. At times, reference is made to a "bundle of rights", such as the right to set the agenda, to allocate resources, and to design and implement development programs (Lavergne, 2003). As a result the concept of "local ownership" is relevant in our attempt to describe and analyse the process towards greater autonomy in higher education institutions in Indonesia because the transition implies a move from centralized to decentralized decision-making.

These intersecting dimensions, developments towards decentralization and (regional) autonomy in Indonesia and the "global" tendencies towards greater effectiveness of public institutions are best understood from an organizational embeddedness approach. At an 
institutional or organizational level this implies awareness of the interrelatedness of power, culture and organization (Dacin, et.al., 1999). However, embeddedness here also denotes sensitivity for the interrelatedness of global and local processes in organizational change in higher education institutions (Vaira, 2004). This is where this article contributes to furthering our understanding of change in organizations by employing a more holistic approach (in fact cultivated by anthropology), incorporating not only the dynamics between agency and structure but also by "contextualizing" institutions, i.e. paying attention to political, social, cultural, economic and historical dimensions.

The case we explore in detail concerns eight higher education institutions in Eastern Indonesia, four public universities and four public polytechnics, each of which is in the process of change towards "greater autonomy" (assisted by the Centre for International Cooperation of VU University Amsterdam, the Netherlands). Some of the weaknesses ascribed to these institutions include: centralized management, ineffective institutional leadership, ineffective human resource management due to limited numbers of skilled staff, limited supporting infrastructure, lack of funds to upgrade staff, lack of internal audits, and so on (Nuffic 2008a, 2008b). The question we address is: How do higher education institutions in Eastern Indonesia perceive and anticipate their role in the process towards greater autonomy?

The remainder of this article is structured as follows. The next part discusses decentralization processes globally as well as within the Indonesian context. This is followed by a discussion on Indonesian higher education and on the Eastern Indonesian institutes involved in the research. Next, we introduce our research approach. The core part of the article presents the findings on the perceptions of staff members of several Eastern Indonesian higher education institutions about the change towards greater autonomy. We conclude with a discussion of our findings.

\section{DECENTRALIZATION AND AUTONOMY}

It is commonly agreed that the last two decades have witnessed the increasing marketization of public institutions driven by such issues as global processes of deregulation, downsizing of social services, privatization and reduced public spending (Antlov, 2002). In Asia these processes took the form of a decentralization wave that was strongly encouraged by international agencies such as the World Bank and IMF. The pressure to decentralize was so intense that "governments that did not embrace decentralization risked losing legitimacy in international circles" (Bjork, 2004, p.248). Delegating authority to local levels is considered to be a more efficient use of resources and human capital.

The decentralization and privatization wave also impacted on organizational change in higher education institutions. Vaira (2004) argues that these global trends have created "meta-myths" of the minimalist state, entrepreneurialism, and the knowledge society. These myths however, have consequences for the organizational arrangements and social legitimacy of higher education institutions (Vaira, 2004, p.488). These rationalized myths that denote increasing decentralization, shrinking public expenditure, more confidence in the market, a business ethos, meeting demands, competitive advantages, and knowledge production have become an "objective reality" that travels across the world by means of institutional carriers like UNESCO, the World Bank, IMF, OECD. These institutional carriers "define, translate and disseminate these myths worldwide" and "they define the appropriate and legitimate form for higher education in the global age" (ibid.). It also implies that these myths are by now very "real" and in fact no longer are myths in that respect. As Vaira points out, emergent countries are particularly prone to 
submit to these trends, as their financial support is often conditional, almost in a quid pro quo manner. In other words financial loans go hand-in-hand with pressure from institutional carriers "regarding the nation-state's institutional and organizational structure" (ibid., p.491). This clearly applied to the Indonesian case in the late 1990s, when the external pressure for more structural adjustment in the wake of the Asian crisis were, "a further reason for the shift towards privatization" (Welch, 2007, p.666). Indeed, the Asian crisis meant substantial financial support for Indonesia from the IMF and World Bank with the prerequisite of structural adjustments. For example, on 5 November 1997 the IMF announced a package including stand-by credit of \$US10.14 billion for Indonesia. The rest of the package included private sector participation in infrastructure; expanding the privatization program; and increasing the transparency of public sector activities to enhance the quality of governance (taken from www.aph.gov.au).

Besides the global trend towards decentralization and autonomy, there is also a "local" history of ongoing decentralization efforts in Indonesia itself. Even though the country could, until quite recently, be characterized as one of the most centralized nations in Asia, decentralization discussions and attempts date as far back as 1903, when the first decentralization law was issued (Decentralization Law of the Netherlands Indies). Several decentralization stipulations followed, both under Dutch colonial rule as under the first Indonesian president Sukarno, but decentralization has never been the outcome (Buising, 2000).

The renewed and intensified decentralization efforts of the late 1990s in Indonesia are best understood within the political and economic turmoil of the late 1990s. Thirty years of political suppression started to take its toll on the ruling president, Suharto (1966-1998), in particular with the rise of the Indonesian Democratic Party (under the leadership of Megawati Sukarnoputri) and its demands for democracy and human rights. The volatile political situation (aggravated by turmoil in East Timor, now an independent state) led to an explosion of protests in 1997 when an economic crisis hit several Asian economies, including that of Indonesia. Within weeks the rupiah reached a historic low, whilst food and fuel prices skyrocketed. People went to the streets and demanded reforms, access to the riches of their own provinces, and the termination of the authoritarian, top-down, New Order regime. Suharto had to step down in May 1998.

Under interim president Habibie (1998-1999) a team started to structure the reform and developed a bill that stipulated the devolution of power to the regions (Smith, 2008). This resulted in the passage of two laws in 1999; Law 22/1999 on Regional Governance and Law 25/1999 on Fiscal Balance.1 Law 22/1999 is the one stipulating regional autonomy (otonomi daerah). This regional autonomy project was described as "the world's largest political decentralization project" and involved the transfer of some two million civil servants from the central level to the regency and municipality level, and the control of over $40 \%$ of government expenditures and $60 \%$ of the national development budget (Smith, 2008). In this case, decentralization and regional autonomy are closely related (Aspinall, 2005; Vickers, 2005; Turner and Podger, 2003; Kingsbury and Aveling, 2003; O"Rourke, 2003). Some argue that the demand for decentralization set into motion the process of autonomy. For example, Suwondo (2002, p.1) refers to regional autonomy in Indonesia as "management by local governments that obtained "power" through decentralization". Although regional autonomy was installed by law in 1999, it is still hotly debated today and many controversies abound:

"The practice of regional autonomy has strayed far from its initial path," Ryaas Rasyid, a former director general of regional autonomy and minister for bureaucratic reform, told an audience of regional representatives during an 
overview at the State Administration Institute in Jakarta on Wednesday. After the fall of Soeharto's New Order regime, the country's centralized governance system gave way to regional autonomy, a system in which regions have more authority to manage their own affairs such as budgeting and lawmaking. According to Ryaas there has been no real improvement on the whole in either management or welfare within the regions. [The Jakarta Post; 3 June 2009]

Interim reports on the decentralization process often refer to the fact that most people were unaware how to proceed with implementing decentralization, as they had no experience with issues of supervision and accountability under the top-down New Order regime. It is argued that, "they never participated in decision- making processes" and that "they do not have the courage, the willingness and the capability to materialize their sovereignty" (Suwondo, 2002, p.9). Although not uncontested, conclusions like these set the stage against which the push towards greater autonomy in Indonesia, and in particular the move towards academic and financial autonomy in higher education, must be explored.

\section{HIGHER EDUCATION IN INDONESIA}

Higher education in Indonesia emerged in the late $19^{\text {th }}$ Century (1885) with the establishment of the first higher education institution by the Dutch colonial government, aimed at the training of indigenous doctors. Private higher educations institutes in Indonesia pre-date public institutions and are seen as having fulfilled a prominent role in the development of Indonesia's higher education system. During the nationalist fervour after independence (1945) a merger of private institutes meant the establishment of the first national public university, the Gadjah Mada University in Yogyakarta. Political aspirations in the 1960s were aimed at establishing at least one public university in each province and indeed 23 new universities, institutes, and teachertraining colleges were established during that period. This also meant a move to more inclusive higher education. In the 1970s and 1980s, supported by large oil revenues, Indonesian higher education expanded rapidly (Nizam, 2006, p.35-36; see also Wicaksono and Friawan, 2008).

Since 2003 there are five different types of organizations (both private and public) that are considered to be higher education institutions in Indonesia: academies, polytechnics, advanced schools, institutes and universities. There are far more private institutions than public ones; in 2004 the numbers were 2,235 versus 81 respectively (Fahmi, 2007, p.4); in 2010 3,020 versus 83 (DGHE, 2011). Moreover, the student population in higher education institutions has been growing from 200,000 in 1975, to 2.5 million in 1995, 3.5 million in 2005 and 5.2 million in 2010 , with the gross enrolment rate for higher education in Indonesia up from 12,8 percent in 2000 to 24,67 percent in 2010 (Task Force Higher Education, 2000, p.8; DGHE, 2011).

An important central body in Indonesia's higher education system is the Indonesian Directorate General of Higher Education (DGHE). In 2003 it launched a new higher education long-term strategy (2003-2010) that deals with autonomy, quality, access, and equity issues (DGHE, 2003). The process of regional autonomy also has implications for the role of the central government, represented by the DGHE, which is meant to transform from a regulating role into one of empowering, enabling and facilitating. This transformation also demands that the responsibility and accountability will become a core task of the higher education institutions themselves. Through the long-term strategy the DGHE wants to realize a higher education system characterized by high quality, guaranteed access for education participants who fulfill the 
requirements, and an autonomous status that will enable them to manage their own organization and sources of income, and which will guarantee efficient and effective implementation of academic activities (DGHE, 2003; Nuffic, 2008a,b).

In 2000 four of the most established public universities, University of Indonesia (Jakarta), Bogor Agricultural University (Bogor), Bandung Institute of Technology (Bandung) and Gadjah Mada University (Yogyakarta), were selected as forerunners to become new legal entity universities. A new government regulation (PP 61/1999) was introduced to pave the way to transform state/public universities into autonomous universities called 'state legal entity university". They would no longer be part of the government but would become responsible to the public. Funding problems and inadequate legal support however turned out to be major bottlenecks in this transformation process (Beerkens, 2002; Nizam, 2006; Wicaksono and Friawan, 2008).

According to a study by the Nuffic (2008a,b) compared to other ASEAN countries, Indonesian higher education institutions perform relatively low in terms of participation and output. Mismanagement in Indonesia's higher education is said to be one of the contributing factors to this situation. The management is too centralized and the government treats the higher education sector in the same way as other government agencies. The centralized system led to a bureaucratic working atmosphere in higher education institutions with a tendency of responsibility towards the person in charge rather than to stakeholders.

According to an evaluation report (Nuffic, 2008a, 2008b) the current situation in Eastern Indonesian higher education is, not conducive for a process of organizational development towards institutional autonomy, and can be characterized by a long list of general deficiencies: ineffective and inefficient university governance, high dependency on government budget, poorly managed assets and limited staff capacity. The institutions in Eastern Indonesia have little experience with strengthening institutional management, in terms of planning, organization, leadership \& management, decision-making and standard operating procedures. Furthermore, awareness and commitment of staff is seen as an issue since many have additional jobs outside their institutions (Nuffic, 2008a, 2008b). It has to be contextualized that the higher education institutions in Eastern Indonesia are often situated in remote locations, suffer from natural disasters, socio-political unrest and power cuts. Being far away from the centre, (the distance between Jakarta and Eastern Indonesia is some 2,550 to 3,000 kilometers), has had a profound impact on the development of these "outer" islands.

In order to acquire the necessary status as autonomous institute with a Legal Entity the higher education institutions must follow certain steps and comply with a set of criteria, such as cooperation with peer organizations, institutional capacity building, good governance, human resource development and quality assurance, and thus, the road to autonomy, at least for the Eastern Indonesian institutions, appears to be quite long.

In summary, the post-1998 events in Indonesia as well as the pressure of international agencies had an accelerating effect on reforms in higher education; as argued by Beerkens "increasing university autonomy was in line with the IMF reform packages" (2002, p.24). However, autonomy in higher education institutions in Indonesia, as an example of greater moves towards regional autonomy is an interesting mixture of global and local forces at work:

"given the strong tradition of centralism in Indonesia, where power, influence and money flow from Jakarta, recent moves towards "big bang" decentralization and increased competition in education, urged by international agencies but given 
greater impetus by the severity of the economic crisis, are apt to be poorly understood in the regions" (Welch, 2007, p.666).

Such a conclusion demands to be investigated in more detail. The project involvement of the Centre for International Cooperation (CIS) with four universities and four polytechnics in Eastern Indonesia provided the opportunity to critically assess these developments and more importantly to monitor how within the process of decentralization, greater autonomy is perceived, received and experienced. As mentioned above, the aim is to come to a better understanding of the manner in which higher education institutions in Eastern Indonesia are reflecting on the challenges towards greater autonomy.

\section{RESEARCH APPROACH}

Based on the duality of structure and agency as developed by Giddens (1984), institutional theory over the years has moved towards incorporating agency, power and conflict (DiMaggio, $1988 ; 1991)$ in the study of institutions and institutional arrangement. According to Scott (2008, p.431) these developments established the thinking that "institutional processes operate not only in a top-down, but also in a bottom-up direction". The recent trends are not only more agency focused, "in practice, a given institution only comes into being, becomes reified and later dereified through the actions of agents who seek control". It also adheres to the organizational (institutional) field approach meaning that "agentic experience is characterized by a constant switching back and forth across a complex tapestry of institutional contexts" (Mohr and White, 2008, p.508). These newer directions in institutional theory (Mohr and Friedland, 2008), also exemplified in the emergence of the concept of institutional entrepreneurship, that reintroduces agency, interests and power into institutional analyses of organizations (Garud, Hardy and Maguire, 2007, p.957), seem to resonate with work on organizational embeddedness. Organizational embeddedness implies taking context serious by incorporating in the analysis of management and organizations for instance historical, political and cultural systems of meaning; national and sector specific circumstances; inter-actor and interorganizational relations and networks; and social activity and agency (Dacin et al., 1999). Dacin et al (1999) demonstrate that embeddedness thus draws the attention to questions of culture and power and to relational aspects of organizations. The institutional and embeddedness approach point towards an understanding of higher education institutions as embedded in local and global contexts and as consisting of actors and processes of meaning-giving in their own regard.

The empirical data used in this article were collected through open-ended questionnaires at the four universities (Undana, Unpatti, Unkhair and Uncen) and four polytechnics (Politani, PNK, Polikant and Polnam) in Eastern Indonesia that are currently partners of CIS. As briefly touched upon above, CIS is involved in two projects (funded by the Dutch government) concerning strengthening the institutional management of these universities and polytechnics in nine specific areas, which are: governance, leadership, HRM, financial management, revenue generation, facility \& asset management, information management, academic quality assurance and administrative quality assurance. Although the projects do not have an explicit aim of developing autonomy in these institutions, it is foreseen that that they may help to begin this process.

The projects provided access to the data as collected for the purpose of this research. Questionnaires have been developed and translated into Indonesian in close collaboration with local (Indonesian) consultants and were distributed to the members of "change teams" in the 
universities and the polytechnics (as established in the two projects). The members of these "change teams" occupy a variety of academic and non-academic positions. A number of questionnaires have also been collected during workshops at two universities (Unpatti, Ambon and Unkhair, Ternate). In addition, a lecturer from Unkhair voluntarily collected some questionnaires from colleagues. An Indonesian lecturer from Undana supported the translation of the responses into English. Other inputs have been collected during face-to-face interviews and workshops in Eastern Indonesia, and include personal observations and experiences from the authors, regarding the situation in the institutions under study as well as on the broader Indonesian context in which this takes place. All data were collected in the period between October 2008 and December 2009.

The focus in the data gathering process (both primary and secondary) was on the sensemaking of the various actors in the process towards greater autonomy. The questionnaires addressed the move towards autonomy at three levels; a more general part asking about the development of autonomy in higher education (the why of the autonomy discussion and its origins); an institutional dimension (challenges and obstacles for the specific institution, possible support the institutions are receiving, what the institutions have been doing so far); and an individual line of inquiry (ideas about the impact of the suggested change for work-related issues of the employees).

In total, 29 questionnaires have been collected, almost equally spread over the universities on the one hand and polytechnics on the other. From these questionnaires, we distinguished three groups of respondents: a management group consisting of rectors, vice-rectors, directors, vicedirectors, deans, and vice-deans ( 9 responses); an academic group of lecturers and researchers (12 responses); and an administrative group with project coordinators and support staff from service departments ( 8 responses). Following organizational embeddedness, these three respondent groups allow us to understand local perceptions of autonomy from different professional angles within the higher education institutions. Methodologically, it could have been interesting to distinguish between data collected at universities on the one hand and polytechnics on the other. However, without saying that there are no differences, we have not come across significant discrepancies and therefore will not present the data based on this division.

The analysis follows the standard qualitative methods of analyzing from open coding to more selective coding (Miles and Huberman, 1994; Ritchie and Lewis, 2004). This implies that the themes of the short questionnaires are also the tools for the (comparative) analysis in terms of consistencies and inconsistencies. This approach is appropriate for the explorative character of the research. As such no claims are made about the representative nature since this is beyond the epistemological point of departure, the aim being to gain a better understanding of sense-making.

\section{FINDINGS: HIGHER EDUCATION AUTONOMY IN EASTERN INDONESIA}

In this section we will explore how the staff of polytechnics and universities in Eastern Indonesia perceive autonomy, and how they (and their institutions) anticipate their role in the process towards greater autonomy. As outlined above we will explore what they think has inspired the shift towards autonomy, the main challenges and obstacles for the institutions, and the manners in which the shift is perceived to affect individual staff members. 


\section{The Shift Towards Autonomy: Threats and Challenges}

In general, the respondents believe that the development towards autonomy comes from the Indonesian government, or to be more specific, from the Directorate General for Higher Education. Some respondents from the management group argue that the development towards autonomy should be considered as a response to international developments and global competition, influenced by autonomous higher education institutions in America and Europe. Several respondents from the groups of academics and administrators refer to discussions with the more advanced universities and other stakeholders in the higher education sector in Indonesia in the early " $90 \mathrm{~s}$, who appeared to be the early protagonists of autonomy. These advanced institutes believed that they should be autonomous and be able to manage their own affairs without any interference from the central government. One administrator explains:

"Then, in 1996, the DGHE officially accommodated the ideas within the Higher Education Long Term Development Framework (1996 - 2005), outlining a new paradigm for university management, stressing autonomy as the most important prerequisite for the achievement of continuous quality improvement".

The respondents have quite comparable ideas about the goal of increased autonomy: institutional autonomy should eventually have a positive effect on the quality of education. All respondents consider autonomy as empowering, enabling the institutions to achieve objectives and targets in a more creative and innovative way, thereby responding to local circumstances and needs. In addition, respondents from the academic group emphasize the expected enhanced possibilities for further professional development and the possibility to improve the welfare of staff. They are also quite explicit about their desire to become independent from the state and to do away with all the bureaucratic influence and centralistic interference from the government.

Most respondents are generally positive about the development towards autonomy. However the biggest perceived challenge (mentioned by respondents from all groups) is to assume full responsibility for the entire well being (organizational health) of their institutions and staff. Mainly administrators expect higher demands from the government in terms of rules and regulations for transparency and accountability, in return for greater autonomy.

Almost all respondents mention serious threats and obstacles that may constrain the process of becoming an autonomous institution. The most important threats relate to limited awareness and inappropriate mindset (and subsequent behavior) among staff, inadequate organizational structure, weak leadership and management practices, inadequate assets and facilities and the socio-economic disadvantages of their geographically remote locations.

During a visit to a more advanced polytechnic (Polman) in Bandung, it became clear that there was much confusion (among the polytechnics) about the practical implications of becoming a Legal Entity, especially in terms of rules and regulations for HRM and finance, and also about the process towards achieving such a status. Lecturers from universities in Eastern Indonesia have also expressed the need for a well-disseminated and deep understanding of (the road towards) increased autonomy in the questionnaires.

A striking number of respondents (from all respondent groups) refer to mental and behavioral constraints like lack of discipline, low motivation, low morale, lack of commitment, disobedience, unfairness and even laziness. One administrator refers to unwillingness of staff and remarks: 
"Autonomy becomes a threat especially for the higher education institutions with unenthusiastic staff, working in just-routine environments without any creative and innovative performance."

During a workshop at a polytechnic in West Timor, the participants were asked whether they perceive autonomy as a challenge or as a threat, and one participant vividly explained: the government is like a mother for us... and will always take care of us. While saying this, he acted as if he was holding a baby in his arms. Although this attitude might not be very conducive for the development towards greater autonomy, the expression is quite understandable from a historical perspective. Others expressed similar issues of the prevailing civil servant mentality as an obstacle to achieve greater autonomy.

Several academics are of the opinion that the existing organizational structures are too bureaucratic, ineffective and inefficient. All respondents consider management practices problematic when they mention the very rigid bureaucracy and long lines of control. One academic explicates:

"We have to change all aspects of the day-to-day business of our activities. Meeting the requirements of a scheduled agenda on time, transparency, accountability, fairness, and responsiveness. All these features are currently not being practiced."

This quote shows that even the most basic managerial systems and practices are lacking. Academics mentioned that problems are not always addressed directly, but shifted all the time and we are not consistent in planning and implementation. Standard operation procedures in areas like HRM and financial management are weakly developed, although several higher education institutions are making some attempts to gain ISO 9001 certification for quality management.

Several respondents from the academic and administrative groups seem to agree that leadership is sometimes lacking or problematic. As an administrator indicates:

"The main problem of the university is how to change the mindset of the managers, who used to work in a rigidly regulated atmosphere."

In addition, an academic argues that managers tend to display similar hierarchical and normative leadership styles just as their former leaders did. Several academics state that the current government regulations prevent young but competent and enthusiastic staff to become a manager. All respondents mention the inadequate assets and facilities of their institution. Buildings are not well maintained, and in many cases facilities are lacking, old fashioned or run down. This state of affairs is not conducive for quality improvements in teaching and learning.

The majority considers autonomy in particular an opportunity for the larger and more advanced institutions in the densely populated and industrialized areas of Java and Sumatra. The contrast with the higher education institutions in Eastern Indonesia, however, could not be bigger: remote and sparsely populated low income regions, far away from the heart of political and economic activity, combined with little industry and trade. This has far-reaching consequences for the viability of autonomy. First of all, future government funding will be based on student numbers, but if there are not many students, it will be problematic to receive many funds. In 
addition, competition between the institutions for students and investment funds from the government will increase. Secondly, regional income generating opportunities are supposedly scarce. Thirdly, the schools and universities cannot raise admission fees for the students, as the poor communities in the neighboring villages cannot afford to pay them. As a result, it will be difficult to find the necessary resources for sustainable development and improvement of adequate assets, facilities and staff.

As far as academic affairs are concerned, managers and academics seem to agree in many respects; they all argue that "curricula of study programs are out of date and do not meet the needs of the labor market." In addition, a Legal Entity status requires that all lecturers have an MSc, MA, MBA or equivalent degree, which many of them do not have. Qualified lecturers may leave for other, more established, institutes with better facilities and higher salaries. Some academics refer to a lack of policy and procedures in all academic matters, including quality assurance, while others say that the academic atmosphere, referring to staff and students, should become more open and disciplined. Another threat seems to be represented by the students:

"After the door for autonomy was opened a few years ago eagerness for autonomy grows, yet opposition remains especially from students.... we may have to raise student fees; therefore students do not support autonomy."

Of course, the list of threats and obstacles as described above is not exhaustive but it presents insights into the most important concerns of the various (groups of) respondents.

\section{Preparing for Change?}

Next we will explore what the institutions are currently doing (or have to do in the near future) in order to prepare for greater autonomy, and also what kind of internal and external support they deem important.

When asked what the institutions have to do in order to achieve institutional autonomy, many respondents refer to (ways to address) the same challenges, threats and obstacles that have already been described in the previous section. This time, however, the responses are more oriented towards the future and include new lines of thinking.

All respondents argue that it is of utmost importance to enhance the awareness and understanding of staff and to change their mindset and behavior; everyone should know what greater autonomy means for the institution and for each individual staff member. According to some, this can be achieved through internal dissemination sessions. There is also much agreement on the need for improved work ethics, in terms of commitment, discipline and loyalty of staff. One academic explains that there is a need for a change of culture. Interestingly, many respondents suggest that strong management is needed to change the current work ethics, but at the same time, a number of responses imply that the current leaders and managers are not capable of doing so.

The respondents often mention arguments referring to the organizational structure and to leadership and management issues. Many argue in favor of restructuring the organization by making it smaller and more effective and more efficient. A number of positions and functions may disappear which, according to one respondent from the management group, has a negative effect on the attitude of some staff members towards greater autonomy. General ideas on institutional leadership and management are the need to strengthen leadership in order to build a 
more professional institution and to control the performance of staff. Almost all respondents emphasize that especially financial management must become more accountable and transparent.

A few academics and administrators argue that a strategic road map towards autonomy is needed, covering all organizational and managerial aspects of the institution. Such a roadmap would include policies, systems and procedures for every domain of institutional management. One administrator refers to the Higher Education Long Term Development Framework (1996 2005) by the DGHE in 1996, and argues that:

"The university has to change and adopt the new working paradigm. The university should strengthen institutional management, improve the capacity of its human resources, become more effective and efficient and become more creative in seeking alternative funding sources."

All respondents stress the importance of involving external stakeholders in their operations: government, the business sector (industry, trade organizations, small and medium sized enterprises), communities, national and international higher education institutions, all these external stakeholders can provide support in some way and help them to develop further. The local government can provide funds and political support, the business sector can help in the development of labor market oriented programs and provide opportunities for revenue generation, and collaboration with more advanced institutes may result in new experiences and opportunities for professional staff development. But then, the institutions need to become viable and the academic staff needs to become more innovative and creative:

"It is very important for the university management to push the staff to change their mindset, from the civil servant into the entrepreneurial mentality and behavior. University experts and expertise should become the most important agent for revenue generation and will support all programs and developments."

Academics argue that, in addition, assets and facilities have to be upgraded and quality assurance mechanisms have to be put in place.

The higher education institutions have many ideas about how to anticipate the change towards greater autonomy; they know what is wrong, what is lacking and also what has to be changed. However, not many concrete ideas on how to realize them came forward, although we should add that no specific question towards this end was included in the questionnaire.

Respondents from all groups seem to be well aware of the potential risks of greater autonomy for the existence of their institutions and for their jobs. Individual staff members realize they must increase their performance and contribute to a sustainable development of their institution if it wants to be able to compete with other higher education institutes.

In terms of achieving the Legal Entity status, employees of higher education institutions will no longer be civil servants, but employees contracted to their university or polytechnic (private status). Respondents realize that they have to learn to work in a more professional way, that they will have to comply with rules and procedures and become more result oriented. Academics are trying to apply for MSc and MA programs in order to remain qualified as a lecturer. In the near future, students may evaluate the didactic performance of lecturers. Both academics and administrators fear performance based remuneration and punishment when they do not perform well enough. Others say that weak performing staff members may be requested to go on early 
retirement and un-committed staff may even be dismissed. On the other hand, well performing staff members may receive a higher salary. According to many academics, these changes altogether will create a more professional work climate in the Eastern Indonesian higher education institutions.

\section{TRAVELING TOWARDS GREATER AUTONOMY: A BUMPY ROAD}

The above results show an interesting mix of perceived challenges and threats. We will evaluate the findings according to the perceptions about the "why" of autonomy and the expressed challenges for institutional and personal positions.

The respondents from the institutions involved in this research generally interpret the development towards decentralization and autonomy of Indonesian higher education as instigated by the central government in Jakarta. Some mentioning of global processes is made but in general the feeling is that "it" comes from "the centre". No explicit mentioning was made of institutional carriers like the World Bank, or to earlier decentralization efforts from the Indonesian government (before and during the era of reformasi). Hence, we can detect some discrepancies between perceptions within the Eastern Indonesian higher educational institutes and the reports and publications of both Indonesian and non-Indonesian scholars and experts, who often refer to the globalization of higher education and the pressure of institutional carriers as reasons for decentralization and greater autonomy. Looking at the long history in Indonesia of top-down governance and the relationship between "the centre" (Jakarta, Java) and "the rest" of Indonesia it might be argued that the overarching frame of reference is that the central government decides. This is the default framework in which control, power and decision-making are connected. The New Order regime not only systematically banned all forms of political participation over a period of more than thirty years; the top-down management also meant that decision-making was mostly someone else's affair. It can be argued that this has left its marks on the generation that is now asked to implement autonomy and take responsibility for new forms of decision-making. This is not to argue that there is a lack of capacity or capabilities, it seems much more an issue of "lack of experience" in taking "matters into one's own hands"; a question of local ownership (Singh, 2002).

Hence we can see a discrepancy between arguments in the literature that globalization, new public management discourse, and structural adjustment programs (World Bank and IMF) are the carriers that have pushed forward the development towards greater autonomy of higher education in Indonesia (Task Force Higher Education, 2000; Verheul, 2001; Nizam, 2006; Beerkens, 2010) and the perceptions within the local institutions of this research who relate the move towards greater autonomy to the central government in Jakarta. The fact that these institutions are in the "periphery" whereas studies carried out so far mainly concern institutions at the core (Indonesian elite) might be part of the explanation.

In terms of institutional and personal challenges, the move towards greater autonomy is perceived as opening up possibilities for empowerment, an increased ability to respond to local circumstances, less interference from the government, and opportunities for professional development and staff welfare. The respondents frequently mentioned the need for "mind-set" and "work-ethos" changes among managers and academics who needed to become more entrepreneurial and professional. Interestingly enough, the rhetoric used by the respondents reflects the global discourse of new public management, while they position the rationale for 
greater autonomy more firmly in national politics (the centre, Jakarta decides), although obviously the two are not mutually exclusive.

Many respondents realize the enormous challenge of taking full responsibility for the well being and further development of their institutions, but they are also aware of the many threats and obstacles towards greater autonomy, such as legal, financial and employment related changes. It is quite clear that these institutions are in the middle of a transition phase; old habits and new challenges are continuously weighted for their benefits and losses.

In line with the expectations from the respondents in our research, the change of employment status from civil servants to university employees, has created a heated debate within the broader Indonesians academic community, "many fear that the change in employment status will restrict academic freedom and create a more industrial approach in staff relations generating layoffs and deteriorating services" (Nizam, 2006, p.55). This fear, especially among academics, may influence their attitude towards greater autonomy, "the buffer created by the academics in the past to resist political influence [from the government], is now often used to avoid institutional managerialism" (Beerkens, 2010, p.385). It is interesting that the results show an expressed need for stronger and more professional leadership in order to make the changes possible while at the same time it is questioned whether the present generation of managers has the mind-set to do so. Hence, strong academic leadership is expressed as an indispensable factor in the process towards greater autonomy.

This "skill" problem is often mentioned in reports on higher education in Indonesia. The Task Force Higher Education (2000) presents a long list of widespread constraints in Indonesian higher education institutions, relating to staff absence, lack of commitment, limited ownership and accountability, as a result of which talented academics have left or become over-involved in off-campus activities. Indeed, many academics have other jobs in local government agencies and the private sector, often explained by the poor salaries that are being paid by the public institutions. Writing on the more recent situation these problematic academic working conditions are also acknowledged by Buchori \& Malik (2004) and by Wicaksono \& Friawan (2008), indicating that not much has changed so far. Nizam (2006, p.37) argues that the centralized system that was adopted over the past decades has created a system characterized by inefficiency and poor initiative: "bureaucratic reliance on central authority has not enabled higher education institutions to respond to external changes or receive timely support." He continues by arguing that the old system guaranteed lifelong employment while issues of accountability were rarely discussed, "under such a situation, discipline was difficult, academic freedom was often misused, and the profession was characterized by absenteeism and low performance" (ibid., p.54).

Nevertheless, it is not only institutional and personal issues that create apprehension. Staff of the Eastern Indonesian institutes in this research perceives issues of vagueness and ambiguity to be significant. As a result many are grappling with what is expected of them because they are confronted with unclear policies and procedures. The impressions from the workshops that were held at the higher education institutions indicate that many people do not know where to start, or what to do differently and how. In particular legal and financial issues are considered problematic, which was also the greatest obstacle for the four universities on Java that were selected as pilot cases in the move towards greater autonomy in 2000 (Wicaksono and Friawan, 2008). The fact that Indonesia is in the middle of what is called the world's largest political decentralization project (Smith, 2008) might explain some of these obstacles. The questionnaires point towards problems with vague procedures, the large number of subsequent government regulations, laws, policy frameworks and succeeding long-term strategies for higher education, 
but also that there is lack of vision on the how and why of greater autonomy. In the words of a higher education consultant, "the lack of direction by the DGHE and decision making at the central political level, and the absence of enabling laws for staffing (phasing out civil servants) and finance (introduction of block grants and transfer of assets) have negatively influenced the autonomy process" (Nuffic, 2008a, 2008b). It can also partly be related to the typical policy making processes in Indonesia characterized by the divergence between what might work in the more established environment of the centre (Jakarta, java) does not necessarily work in its eastern parts. In a country with such wide diversity as Indonesia, uniform policies can be quite problematic.

The recent (2010) decision by the Indonesian Constitutional Court to annul the Legal Entity law has exacerbated the already existing chaos. According to this judgement the law is unconstitutional as it violates the citizen's right to be guaranteed education by the state. Furthermore, the Court has argued that there is obvious disparity in the capacity of state universities in the country to comply with the law (The Jakarta Post, 1 April 2010). However, the Deputy Minister of National Education in Indonesia has assured public universities that the recent Legal Entity annulment will not change the government's resolution to make universities more autonomous. A new bill will be drafted that provides a legal umbrella for the measure (Kompas, 7 April 2010).

Financial management and revenue generation are seen as crucial and critical areas for improvement but there are many constraints. Whereas financial management can create a sense of ownership and direct accountability to the granted institutions (Nizam, 2006), experiences from the more established universities make clear that the search for sufficient financial resources has gained priority, "while the mission of serving the society and economy appears to be pushed to the background" (Beerkens, 2010, p.385).

The constraints that have come to the fore, have much in common with decentralization in Indonesia in general such as lack of experience and practice with supervising tasks. Again, the strong suggestion is that because of the centralized governments from before the reformasi, decentralization is a rather unfamiliar phenomenon (Suwondo, 2002). If we combine these insights with the feedback from the respondents, it can be argued that this could very well be an indication of local ownership dilemmas, which make the road towards greater autonomy in Eastern Indonesian higher education institutions rather bumpy.

\section{CONCLUSION AND DISCUSSION}

The aim of this article was to come to a better understanding of the manner in which the process towards greater autonomy in Eastern Indonesian higher education institutions is perceived within the designated institutions. Research has been conducted and open-ended questionnaires and observations took place in eight public universities and polytechnics. The research has been made possible because of the ongoing involvement of the Centre of International Cooperation of the VU University Amsterdam in projects aimed at the institutional strengthening of these higher education institutions.

What we have denoted as the move towards greater autonomy in Indonesian higher education can only be understood by departing from an embeddedness perspective. This implies that the developments described must be positioned first of all, within the "local" Indonesian context characterized by decentralization and reform after a long history of authoritarian rule and centralized governance and the subsequent "ownership" problems that have arisen. Secondly, 
equally relevant for a proper understanding is the "local" Eastern Indonesian context, characterized by a strong centre-periphery legacy of the past which is still felt. Finally, we cannot ignore the debates on the globalization of higher education that have set in motion processes of privatization and entrepreneurialism. Also Indonesian higher education is prone to a new public management discourse stressing market-orientation, competition and professionalism. The conceptual contribution of our article is to be found in this more holistic approach to organizational change.

Reports and articles have appeared that discuss the implications of decentralization and new public management for Indonesian higher education. However, what is missing in these discussions is insight into how all these developments resonate within Indonesian higher education institutions, as they are the ones who have to implement rather drastic changes, in particular in those regions that are far from "the centre" Jakarta. This is where this article finds its empirical contribution as we have tried to incorporate within the discussion not only "voice" but also how the actors involved give meaning to their present situation; how they anticipate their role within the move towards greater autonomy.

Based on the evaluation of the research results, we can conclude that the Eastern Indonesian institutes involved in this research are caught in a situation in which much is still unclear, something that has damaging implications on how the change towards greater autonomy is perceived. In most cases potential benefits of greater autonomy are weighted against the implications thereof for existing practices. Obviously organizational change always carries with it apprehension; positions might get jeopardized, privileges might disappear, and securities might turn out to be less secure than projected. The waves of globalization and the subsequent metamyths that are spread around the world by institutional carriers that proclaim the privatizationage for higher education (Vaira, 2004), have become quite real as the move towards greater autonomy in the Indonesian case exemplifies. But this is only part of the story. Therefore, we proposed an embeddedness perspective that positions the organizational and institutional developments in their proper local and institutional context on the one hand, while taking "agentic experiences" seriously (Mohr and White, 2008). Both have proven their value in arriving at a better understanding of the perceived threats and opportunities in the location under scrutiny.

As to the local context, several of the apprehensions can be explained by the history of depoliticization and top-down decision-making, which have left its marks on practicing "local ownership". Mention is made of an institutional environment (rigid regulations, long lines of command) and an organizational culture (passive mind-set and work-ethos) that are not conductive for pro-active change in a direction that asks for commitment, entrepreneurialism, competitiveness, accountability and transparency, each of which characterise the move towards greater autonomy. However, the "agentic experiences" point out that there indeed is a continuous "switching back and forth" (Mohr and White, 2008). In other words, the actors involved are trying to reposition themselves, looking back and forth on how to incorporate the new without completely disbarring the old. Because, no matter what can be argued against institutional carriers and their homogenization of, in this case, higher education, the move towards greater autonomy as such was not being questioned or judged as unwelcome. Again, here the embeddedness informs us that within the history of the Indonesian context in which there was for a long time no "local power" beyond the New Order bureaucracy blue print, the move towards more autonomy is experienced as empowerment. 
Hence, when considering the current situation in the Eastern Indonesian higher education institutions, the experiences from the more established universities, and the implications of greater autonomy, one can imagine that the road towards autonomy is long and with many hurdles upon it. When referring back to our research question - how do higher education institutions in Eastern Indonesia perceive and anticipate their role in the process towards greater autonomy? - we want to conclude that autonomy is simultaneously being perceived as an opportunity and as a threat; the respondents clearly see the potential advantages of greater autonomy, especially in the sense that they can set their own institutional objectives and try to achieve them in their own way, without (much) interference from the national government. However, there might be costs involved, such as loss of jobs and having to change attitudes and practices. In terms of anticipation, people know what it means and what has to be done in order to achieve greater autonomy. At the same time, we must conclude that for many people in the Eastern Indonesian higher education institutions, the gap between the current situation and the future status of their institution as a legal entity with the responsibility to manage its own financial affairs is quite large. On how to get there and what is needed to indeed achieve greater autonomy, impressions from the research indicate that there is a lot of confusion about the way forward, although the universities may be a bit further ahead of the polytechnics in this respect.

We can conclude that there are clear indications of a strong discursive-cum-travelling power of concepts like decentralization and autonomy, both among international agencies, national task forces and local staff members; rhetoric meets rationale. Higher education in Indonesia is indeed partly influenced by the institutional carriers that take on board such concepts. We have also suggested however, that localized understanding (both regional and institutional) is important. This is also our critique on much of the higher education policies that tend to ignore the local context, making higher education the next best product to be marketed under the reigns of neoliberalism. Therefore, we want to conclude by turning to an argument by Verheul (2001) on new public management in Indonesian higher education policy. He advocates a co-evolution of reforms and context, especially because the Indonesian public sector (including higher education) has a different culture and structure than the countries where the new public management reforms have originated (the West). In his view, a set of conducive contextual conditions has to be developed parallel to the introduction of autonomy. Also, the concept of autonomy itself should be adapted to national idiosyncrasies and cultural values. Based on this preliminary and explorative research we tend to agree. However we are also inclined to ask whether it is enough of a sensitizing approach as it does not yet do justice to internal power politics, agentic experiences and local cultures.

Based on the above, the conceptual conclusion must be that in order to fully grasp the ongoing dynamics of organizational change (in higher education) and subsequently develop appropriate advice we need a better understanding of the context, the actors, and their interplay.

\section{ENDNOTES}

1. Law 22/1999: Regencies and municipalities will be autonomous regions that are not part of the central government regional administrative hierarchic structure. Law 25/1999: all central government subsidies to the regions are replaced by 'Balance Funds' that include a greater percentage share of building and land taxes, and that now give the regions a set percentage of natural resources, oil and gas revenue produced in the region (Buising, 2000). See also Usman (2002).।

2. The full names of the institutions involved are: Universitas Cenderawasih (UNCEN), Jayapura, Papua Province; Politeknik Negeri Ambon (POLNAM), Ambon, Maluku Province; Universitas Pattimura (UNPATTI), Ambon, Maluku Province; Politeknik Perikanan Negeri Tual (POLIKANT), Tual, Maluku Province; Universitas 
Khairun (UNKHAIR), Ternate, Maluku Utara Province; Politeknik Negeri Kupang (PNK), Kupang, Nusa Tenggara Timur Province; Politeknik Pertanian Negeri (POLITANI), Kupang, Nusa Tenggara Timur Province; Universitas Nusa Cendana (UNDANA), Kupang, Nusa Tenggara Timur Province.

\section{REFERENCES}

Antlov, H. (2002). The Making of Democratic Local Governance in Indonesia. Paper for the International Workshop on Participatory Planning: Approaches for Local Governance. Bandung, Indonesia, 20-27 January 2002.

Aspinall, E. (2005). Opposing Suharto. Compromise, Resistance, and Regime Change in Indonesia,_Stanford: Stanford University Press.

Beerkens, E. (2002). Moving toward Autonomy in Indonesian Higher Educatio, International Higher Education, Fall, 24-25.

Beerkens, E. (2010). Global Models for the National Research University: Adoption and Adaptation in Indonesia and Malaysia, Globalization, Societies and Education, 8, (3): 369-391.

Bjork, C. (2004). Decentralisation in Education, Institutional Culture and Teacher Autonomy in Indonesia, International Review of Education, 50: 245-262.

Buchori, M. and Malik, A. (2004). The Evolution of Higher Education in Indonesia. In Asian Universities: Historical Perspectives and Contemporary Challenges, eds. P. Altbach and T. Umakoshi. The Johns Hopkins University Press.

Buising, T. (2000). Decentralise. Easy to Say. Difficult to Do. Inside Indonesia, 63 (JulySeptember 2000.

Dacin, T., Ventresca, M. and Beal, B. (1999). The Embeddedness of Organizations: Dialogue \& Directions. Journal of Management, 25, (3): 317-356.

DGHE, (2003). Basic Framework for Higher Education Development KPPTJP IV (2003-2010), Jakarta: Directorate General of Higher Education, Ministry of National Education.

DGHE, (2011). National Coordination Meeting (Rakornas), Jakarta: Directorate General of Higher Education, Ministry of National Education.

DiMaggio, P. (1988). Interest and Agency in Institutional Theory. In Institutional Patterns and Organizations: Culture and Environment, ed. L. G. Zucker. Cambridge, MA: Ballinger.

DiMaggio, P. (1991). Constructing an Organizational Field as a Professional Project: U.S. Art Museums. In The New Institutionalism in Organizational Analysis, eds. W. W. Powell \& P. J. DiMaggio. Chicago: University of Chicago Press. 
Fahmi, M. (2007). Indonesian Higher Education: The Chronicle, Recent Development and the New Legal Entity Universities. Working paper in Economics and Development Studies, Padjadjaran University Bandung.

Garud, R., C. Hardy and S. Maguire (2007). Institutional Entrepreneurship as Embedded Agency: An Introduction to the Special Issue. Organization Studies 28, (7), 957-969.

Giddens, A. (1984). The Constitution of Society. Outline of the Theory of Structuration, Cambridge: Polity Press.

Kingsbury, D. and Aveling, H. (2003). Autonomy and Disintegration in Indonesia, London: RoutledgeCurzon.

Kompas, Indonesian newspaper, 7 April 2010, New legal umbrella for state universities, 12.

Lavergne, R. (2003). Local Ownership and Changing Relationships in Development Cooperation Presented at CCIC/CIDA Dialogue: Local Ownership: Roles for Southern and Canadian Civil Society Organizations, Canadian Council for International Cooperation/Canadian International Development Agency, March, $20^{\text {th }}$.

Miles, M. and Huberman, M. (1994). Qualitative Data Analysis. An Expanded Sourcebook (second edition), London: Sage Publications.

Mohr, J. and Friedland, R. (2008). Theorizing the Institution: Foundations, Duality, and Data. Theory and Society, 37, (5): 421-426.

Mohr, J. and White, H. (2008). How to Model an Institution, Theory and Society, 37, (5): 485512.

Nizam (2006). Indonesia. In Higher Education in South-East Asia, Bangkok: UNESCO Asia and Pacific Regional Bureau for Education, 35-68.

Nuffic, (2008a) The Netherlands Programme for the Institutional Strengthening of Postsecondary Education and Training Capacity (NPT), Project Title: Strengthening Institutional Management at Four Universities. The Hague: Netherlands Organization for International Cooperation in Higher Education.

Nuffic, (2008b). The Netherlands Programme for the Institutional Strengthening of Postsecondary Education and Training Capacity (NPT), Project Title: Strengthening Institutional Management at Four Polytechnics in Eastern Indonesia. The Hague: Netherlands Organization for International Cooperation in Higher Education.

O”Rourke K. (2003). Reformasi. The Struggle for Power in Post-Soeharto Indonesia, Sydney: Allen \& Unwin. 
Ritchie, J. and Lewis, J. (2004). Qualitative Research Practice. A Guide for Social Science Students and Researchers, London: Sage Publications.

Scott, R. (2008). Approaching Adulthood: The Maturing of Institutional Theory, Theory and Society, 37, (5), 427-442.

Singh, S. (2002). Technical Cooperation and Stakeholder Ownership, Development Policy Journal, 2 (Special Issue: Technical Cooperation), 47-71.

Smith, B. (2008). The Origins of Regional Autonomy in Indonesia: Experts and the Marketing of Political Interests, Journal of East Asian Studies, 8, (2): 211-234.

Suwondo, K. (2002). Decentralization in Indonesia. INFID Background Paper on Decentralization, Jakarta: International NGO Forum on Indonesian Development (http://infid.org).

Task Force on Higher Education (2000). Higher Education Strategy: Implementation of the New Paradigm, Final draft, World Bank in cooperation with Bappenas (National Agency for Development Indonesia).

The Jakarta Post, Indonesian newspaper (1 April 2010), Court revokes education entities law, 2.

Turner, M. and Podger, O. (2003). Decentralization in Indonesia Redesigning the State, Canberra: Asia Pacific Press.

Usman, S. (2002). Regional Autonomy in Indonesia. Field Experiences and Emerging Challenges, SMERU Working Paper, (www.smeru.or.id).

Vaira, M. (2004). Globalization and Higher Education Organizational Change: A Framework for Analysis, Higher Education, 48: 483-510.

Verheul, H. (2001). Introducing New Public Management in Indonesian Higher Education Policy: A Co-evolutionary Perspective on Reform and Context, Conference paper for the Fifth International Research Symposium on Public Management (IRSPM V), Barcelona.

Vickers, A. (2005). A History of Modern Indonesia, Cambridge: Cambridge University Press.

Welch, A. R. (2007). Blurred Vision?" Public and Private Higher Education in Indonesia, Higher Education, 54: 665-687.

Wicaksono, Teggu Yudo and D. Friawan (2008). Recent Developments of Higher Education in Indonesia: Issues and Challenges, Eaber Working paper Series, 45, Canberra: The Australian National University. 


\section{Acknowledgement}

The authors would like to thank the two anonymous reviewers for their insightful comments and suggestion, which supported the further refinement of our arguments. 